Research article Open Access

\title{
Parity and breast cancer risk among BRCA1 and BRCA2 mutation carriers
}

\author{
Antonis C Antoniou'1, Andrew Shenton², Eamonn R Maher ${ }^{4}$, Emma Watson², Emma Woodward4, \\ Fiona Lalloo ${ }^{3}$, Douglas F Easton ${ }^{1}$ and D Gareth Evans ${ }^{3}$
}

\author{
${ }^{1}$ CR-UK Genetic Epidemiology Unit, Strangeways Research Laboratory, Department of Public Health and Primary Care, Worts Causeway, University \\ of Cambridge, Cambridge, CB1 8RN, UK \\ 2Department of Clinical Genetics (SM2), St Mary's Hospital, Hathersage Road, Manchester, M13 OJH, UK \\ ${ }^{3}$ Academic Unit of Medical Genetics and Regional Genetics Service, St Mary's Hospital, Manchester M13 OJH, UK \\ ${ }^{4}$ Division of Medical Genetics, University of Birmingham School of Medicine, Birmingham, B15 2TT, UK \\ Corresponding author: D Gareth Evans, Gareth.Evans@CMMC.nhs.uk
}

Received: 26 Jul 2006 Revisions requested: 23 Aug 2006 Revisions received: 20 Nov 2006 Accepted: 22 Dec 2006 Published: 22 Dec 2006

Breast Cancer Research 2006, 8:R72 (doi:10.1186/bcr1630)

This article is online at: http://breast-cancer-research.com/content/8/6/R72

(c) 2006 Antoniou et al.; licensee BioMed Central Ltd.

This is an open access article distributed under the terms of the Creative Commons Attribution License (http://creativecommons.org/licenses/by/2.0), which permits unrestricted use, distribution, and reproduction in any medium, provided the original work is properly cited.

\begin{abstract}
Introduction Increasing parity and age at first full-term pregnancy are established risk factors for breast cancer in the general population. However, their effects among BRCA1 and $B R C A 2$ mutation carriers is still under debate. We used retrospective data on $B R C A 1$ and $B R C A 2$ mutation carriers from the UK to assess the effects of parity-related variables on breast cancer risk.

Methods The data set included 457 mutation carriers who developed breast cancer (cases) and 332 healthy mutation carriers (controls), ascertained through families seen in genetic clinics. Hazard ratios were estimated by using a weighted cohort approach.
\end{abstract}

Results Parous $B R C A 1$ and $B R C A 2$ mutation carriers were at a significantly lower risk of developing breast cancer (hazard ratio $0.54,95 \%$ confidence interval 0.37 to $0.81 ; p=0.002$ ). The protective effect was observed only among carriers who were older than 40 years. Increasing age at first live birth was associated with an increased breast cancer risk among $B R C A 2$ mutation carriers ( $p$ trend $=0.002$ ) but not $B R C A 1$ carriers. However, the analysis by age at first live birth was based on small numbers.

Conclusion The results suggest that the relative risks of breast cancer associated with parity among BRCA1 and BRCA2 mutation carriers may be similar to those in the general population and that reproductive history may be used to improve risk prediction in carriers.

\section{Introduction}

Deleterious mutations in the BRCA1 and BRCA2 genes are associated with high risks of breast and ovarian cancer [1]. However, there is evidence that these risks are modified by both genetic and environmental factors [1-4]. Breast cancer risk in the general population is closely related to reproductive history, and reproductive factors are therefore strong candidates for modifiers of breast cancer risk in BRCA1 and $B R C A 2$ mutation carriers. In particular, increasing parity has been shown to be protective for breast cancer in the general population in many studies [5-7], but its effect among BRCA1 and $B R C A 2$ mutation carriers is still under debate [8-14]. In this report we have used data from $810 B R C A 1$ and $B R C A 2$ mutation carriers from the UK to assess the effect of parity on breast cancer risk.

\section{Materials and methods}

Families with breast and/or ovarian cancer have been tested for BRCA1/2 mutations since 1996 in the overlapping regions of North-West England and the West Midlands, covering about 10 million people. Women attending the specialist genetic clinics in these two regions with a family history of breast or ovarian cancer have a detailed three-generation family tree elicited. If a pathogenic $B R C A 1 / 2$ mutation is identified, further attempts are made to ensure that all individuals relevant to discussions (those who could potentially carry any predisposing mutation) on risk are represented on the family

$\overline{\mathrm{Cl}}=$ confidence interval; $\mathrm{HR}=$ hazard ratio. 
tree. For the purposes of this analysis, pathogenic mutations include frameshift mutations, pathogenic splice variants, large rearrangements, or missense mutations classified as pathogenic by Breast Cancer Information Core [15]. All cases of breast or abdominal cancers are confirmed by means of hospital or pathology records from the Regional Cancer Registries (data available from 1960) or from death certification. Once a family-specific pathogenic $B R C A 1 / 2$ mutation is identified, predictive testing is offered to all blood relatives. Where possible all affected women with breast or ovarian cancer are tested to establish the true extent of BRCA1/2 involvement in the family. In many instances this is done by obtaining paraffinembedded tumour block material from deceased relatives. In many large families it is possible to establish 'obligate' gene carriers by testing for the same mutation in different branches of the family, thereby establishing that intervening relatives carry the same mutation.

All female BRCA1/2 mutation carriers identified by the regional genetics services were eligible for this study; their details and those of all tested relatives and first-degree untested female relatives were entered in a Filemaker Pro 5 database. The initial individual in which a mutation was identified was designated the 'index' case, with all other individuals being classified as to their position in the pedigree compared with a proven mutation carrier. Dates of births for the first and last completed third-trimester pregnancies, before breast cancer, or last follow-up were entered in the database for each of these women. The exception was mothers of a mutation carrier when it was clear that the mutation was paternally inherited. This study was approved by the Central Manchester Local research ethics committee, and participants consented to the Genetics Register research.

A total of 476 BRCA1 and 334 BRCA2 mutation carriers were used in a retrospective analysis of parity. Twenty-one parous carriers with a missing date at first live birth or for whom the age at first live birth could not be estimated from the available data were excluded from the analyses. The remaining individuals were censored (for instance, follow up was completed) at the age of breast cancer diagnosis (457), the age at ovarian cancer diagnosis (138), the age at mastectomy (37), the age at death (31) or the age at interview or last follow-up (126), whichever occurred first. Only carriers who were censored at breast cancer diagnosis were assumed to be affected. Among the $789 B R C A 1$ and BRCA2 mutation carriers included in the analyses, 647 were tested carriers and 142 were classified as obligate carriers by virtue of their position in the pedigree. The carriers originated from 392 distinct families. In all analyses we considered the number of full-term pregnancies occurring before the censoring age.

The effect of parity on breast cancer risk among $B R C A 1$ and $B R C A 2$ mutation carriers was assessed with the use of timedependent Cox regression, and the effects are expressed as hazard ratios (HRs). According to the sampling design, affected mutation carriers may be preferentially sampled. In standard Cox regression the HR is estimated by comparing the distribution of the risk factor among affected individuals with the distribution among unaffected individuals at a particular time point. In the present study design, affected individuals are compared with unaffected carriers who were selected on the basis of their future disease status. However, if a risk factor was associated with breast cancer, then the risk factor would be over-represented among these unaffected carriers (because they would develop breast cancer in the future) and the HR under standard Cox regression would be biased towards 1 [16]. To correct for this potential bias we used a weighted cohort approach to analyse the effect of parity [16]. Under this method, individuals are weighted such that the observed breast cancer incidence rates in the study sample are consistent with established estimates of breast cancer risk among BRCA1 and BRCA2 mutation carriers. It has been shown that this approach gives estimates that are close to unbiased [16]. Weights were computed separately for $B R C A 1$ and BRCA2 mutation carriers by using the breast cancer incidence rate estimates reported in the meta-analysis of Antoniou and colleagues [1].

BRCA1 and BRCA2 mutation carriers were considered in both combined and separate analyses. All analyses were stratified by the year of birth (before 1940, 1940 to 1949,1950 to 1959, 1960 and later) and adjusted for oophorectomy. The joint analysis was also stratified by gene. We allowed for the fact that several individuals may come from the same family by using robust variance estimation $[17,18]$. For direct comparison we present our results in a similar format to that in the report of Andrieu and colleagues [19]. Because only age at first and age at last birth were recorded for carriers with more than two live births, intermediate births were assumed to occur at equally spaced intervals. Analyses were performed with STATA version 9 statistical software (Stata Corporation, College Station, TX, USA).

\section{Results}

Table 1 shows a summary of the characteristics for the affected and unaffected carriers used in the analysis. The mean age at diagnosis for the affected individuals was lower than the censoring age for the unaffected carriers (43.4 and 47.3 years, respectively). The mean age at censoring was similar for $B R C A 1$ and $B R C A 2$ mutation carriers (44.7 and 45.4 years, respectively).

The results of the parity analyses using weighted Cox regression are shown in Table 2. Parous mutation carriers had a significantly lower risk of developing breast cancer ( $\mathrm{HR}=0.54$, $95 \%$ confidence interval $(\mathrm{Cl}) 0.37$ to $0.81 ; p=0.002)$. Having at least one live birth was protective in both $B R C A 1$ and BRCA2 mutation carriers, and the HR did not differ significantly by gene, although the effect was statistically significant 
Table 1

\begin{tabular}{|c|c|c|c|c|c|}
\hline \multirow[t]{2}{*}{ Parameter } & \multirow[t]{2}{*}{ Total } & \multicolumn{2}{|l|}{ Affected } & \multicolumn{2}{|l|}{ Unaffected } \\
\hline & & $B R C A 1$ & $B R C A 2$ & $B R C A 1$ & $B R C A 2$ \\
\hline Number of carriers, $n$ & 789 & 248 & 209 & 218 & 114 \\
\hline Age at censoring, years (mean $\pm S D$ ) & $45.0 \pm 11.3$ & $42.9 \pm 9.6$ & $43.9 \pm 9.3$ & $46.8 \pm 13.0$ & $48.3 \pm 13.0$ \\
\hline \multicolumn{6}{|l|}{ Year of birth, $n(\%)$} \\
\hline Before 1940 & 247 & $78(31.5)$ & $64(30.6)$ & $78(35.8)$ & $27(23.7)$ \\
\hline 1940 to 1949 & 185 & $69(27.8)$ & $61(29.2)$ & $40(18.3)$ & $15(13.2)$ \\
\hline 1950 to 1959 & 169 & $58(23.4)$ & $48(23.0)$ & $34(15.6)$ & $29(25.4)$ \\
\hline 1960 and after & 188 & $43(17.3)$ & $36(17.2)$ & 66 (30.3) & $43(37.7)$ \\
\hline \multicolumn{6}{|l|}{ Censoring age, $n(\%)$} \\
\hline$<55$ years & 670 & $226(91.1)$ & $185(88.5)$ & $172(78.9)$ & $87(76.3)$ \\
\hline$\geq 55$ years & 119 & $22(8.9)$ & $24(11.5)$ & $46(21.1)$ & $27(23.7)$ \\
\hline Oophorectomy before censoring age, $n$ & 45 & 5 & 7 & 25 & 8 \\
\hline
\end{tabular}

only among $B R C A 1$ mutation carriers $(p=0.006)$. When the data were analysed by attained age, parity was found to be protective only among carriers over the age of 40 years $(\mathrm{HR}=$ $0.44,95 \% \mathrm{Cl} 0.23$ to $0.84 ; p=0.013 ; p=0.048$ for the difference in HR between 40 years or less and more than 40 years). For mutation carriers under the age of 40 years, the HR was estimated to be $1.01(95 \% \mathrm{Cl} 0.58$ to 1.76$)$.

There was evidence that increasing number of live births was associated with a decreasing risk of breast cancer in BRCA1 and $B R C A 2$ mutation carriers combined. Each additional live birth was found to reduce breast cancer risk by $10 \%(\mathrm{HR}=$ $0.90,95 \% \mathrm{Cl} 0.80$ to $1.00 ; p$ trend $=0.058$ ). The reduction in risk with each additional birth was similar in BRCA1 and BRCA2 mutation carriers. However, two or more births conferred significantly lower breast cancer risk only among BRCA1 mutation carriers. There was some suggestion that increasing age at first live birth increased the risk of breast cancer among mutation carriers, but this was not statistically significant (for age 30 years or more at first live birth, $\mathrm{HR}=$ $1.30,95 \% \mathrm{Cl} 0.74$ to $2.29 ; p$ trend $=0.38$ ). The effect seemed to be stronger in BRCA2 mutation carriers, particularly for age 30 years and over $(\mathrm{HR}=4.77,95 \% \mathrm{Cl} 2.08$ to $10.94 ; p$ trend $=0.002$ ), but the latter estimate was based on only 32 cases.

\section{Discussion}

It is well established that increasing parity and early age at first birth are associated with a lower risk of developing breast cancer in the general population. There is evidence that the protective effect of parity may be restricted to women who are older than 40 years old [7,20-22]. Our results suggest that parity may have a similar effect on breast cancer risk among $B R C A 1$ and BRCA2 mutation carriers. We found evidence that parous mutation carriers are associated with a lower risk of developing breast cancer and that the protective effect may be limited to carriers above the age of 40 years. This effect was observed only among BRCA1 mutation carriers, but there were no statistically significant differences in the estimates between BRCA1 and BRCA2 mutation carriers. There was no suggestion that parity might increase the risk of developing breast cancer in mutation carriers under the age of 40 years. There was evidence that all levels of parity are associated with a reduced risk of breast cancer among mutation carriers, but this was statistically significant only for carriers with two or more live births. There was also some suggestion of an increased risk associated with first birth after the age of 30 years, again consistent with the effect seen in the general population. However, this effect seemed to be restricted to BRCA2 mutation carriers. This difference might suggest differences in the development of breast cancer among BRCA1 and BRCA2 mutation carriers. Most breast cancer in BRCA1 mutation carriers arises in so-called 'basal' cells that stain positive for certain cytokeratins [23]. It might be that such cells are less responsive to the differentiation induced by pregnancy. However, it should be noted that the gene-specific effects of age at first birth were not a specific hypothesis in this study, and this difference may be attributable to chance.

Several studies, using a variety of designs, have investigated the effect of parity on breast cancer risk among $B R C A 1$ and $B R C A 2$ mutation carriers, but the results have not been consistent. Some studies have not found any significant association with parity $[10,13,14]$, whereas others have reported that parity may increase the risk of breast cancer in mutation carriers $[9,12]$. Among these authors, Jernstrom and colleagues [12] found an increase in risk of breast cancer among carriers under the age of 40 years. However, this association was not 
Breast Cancer Research Vol 8 No 6 Antoniou et al.

Table 2

\begin{tabular}{|c|c|c|c|c|c|c|c|c|c|c|c|c|}
\hline \multirow[t]{2}{*}{ Parameter } & \multicolumn{4}{|l|}{ All } & \multicolumn{4}{|c|}{$B R C A 1$ carriers } & \multicolumn{4}{|c|}{$B R C A 2$ carriers } \\
\hline & UN & $\mathrm{BC}$ & HR & $95 \% \mathrm{Cl}$ & UN & $\mathrm{BC}$ & $\mathrm{HR}$ & $95 \% \mathrm{Cl}$ & UN & $\mathrm{BC}$ & HR & $95 \% \mathrm{Cl}$ \\
\hline \multicolumn{13}{|l|}{ Parity } \\
\hline Nulliparous & 37 & 65 & 1.00 & & 25 & 37 & 1.00 & & 12 & 28 & 1.00 & \\
\hline Parous & 295 & 392 & 0.54 & $0.37-0.81$ & 193 & 211 & 0.53 & $0.34-0.83$ & 102 & 181 & 0.58 & $0.27-1.24$ \\
\hline \multicolumn{13}{|c|}{ Parity by attained age } \\
\hline \multicolumn{13}{|l|}{$\leq 40$ years } \\
\hline Nulliparous & 28 & 44 & 1.00 & & 21 & 24 & 1.00 & & 7 & 20 & 1.00 & \\
\hline Parous ${ }^{a}$ & 76 & 127 & 1.01 & $0.58-1.76$ & 50 & 76 & 1.17 & $0.55-2.52$ & 26 & 51 & 0.72 & $0.42-1.24$ \\
\hline \multicolumn{13}{|l|}{$>40$ years } \\
\hline Nulliparous & 9 & 21 & 1.00 & & 4 & 13 & 1.00 & & 5 & 8 & 1.00 & \\
\hline Parous & 219 & 265 & 0.44 & $0.23-0.84$ & 143 & 135 & 0.34 & $0.16-0.70$ & 76 & 130 & 1.21 & $0.37-3.92$ \\
\hline \multicolumn{13}{|c|}{ Number of live births ${ }^{b}$} \\
\hline Nulliparous & 37 & 65 & 1.00 & & 25 & 37 & 1.00 & & 12 & 28 & 1.00 & \\
\hline 1 & 46 & 57 & 0.62 & $0.37-1.02$ & 27 & 34 & 0.62 & $0.34-1.11$ & 19 & 23 & 0.58 & $0.22-1.53$ \\
\hline 2 & 109 & 167 & 0.57 & $0.38-0.86$ & 73 & 80 & 0.54 & $0.33-0.87$ & 36 & 87 & 0.68 & $0.31-1.47$ \\
\hline 3 & 66 & 79 & 0.64 & $0.34-0.86$ & 42 & 50 & 0.56 & $0.33-0.97$ & 24 & 29 & 0.44 & $0.19-1.04$ \\
\hline $4+$ & 56 & 82 & 0.55 & $0.34-0.91$ & 42 & 44 & 0.51 & $0.29-0.89$ & 14 & 38 & 0.71 & $0.27-1.88$ \\
\hline Per live birth & & & 0.90 & $0.80-1.00$ & & & 0.89 & $0.78-1.01$ & & & 0.93 & $0.75-1.14$ \\
\hline \multicolumn{13}{|c|}{ Age at first live birth } \\
\hline$<20$ years & 61 & 55 & 1.00 & & 38 & 35 & 1.00 & & 23 & 20 & 1.00 & \\
\hline $20-24$ years & 132 & 179 & 1.16 & $0.76-1.78$ & 85 & 92 & 1.08 & $0.65-1.78$ & 47 & 87 & 1.74 & $0.87-3.49$ \\
\hline $25-29$ years & 106 & 108 & 1.13 & $0.72-1.79$ & 73 & 66 & 1.08 & $0.64-1.52$ & 33 & 42 & 1.48 & $0.68-3.22$ \\
\hline$\geq 30$ years & 39 & 50 & 1.30 & $0.74-2.29$ & 25 & 18 & 0.83 & $0.42-1.64$ & 14 & 32 & 4.77 & $2.08-10.94$ \\
\hline Nulliparous & 37 & 65 & 2.09 & $1.26-3.45$ & 25 & 37 & 1.96 & $1.10-3.52$ & 12 & 28 & 2.85 & $1.13-7.15$ \\
\hline
\end{tabular}

$\mathrm{UN}$, unaffected carriers; $\mathrm{BC}$, breast cancer; $\mathrm{HR}$, hazard ratio; $\mathrm{Cl}$, confidence interval. aAnalyses not adjusted for oophorectomy (all others adjusted). Overall analysis stratified by year of birth and gene. ${ }^{b}$ Assuming that births between first and last birth were equally spaced; 25 carriers ( 7 affected, 18 unaffected) with missing age at last birth were assumed to be nulliparous until age at first birth and were then considered as a separate category (hazard ratios not shown).

present in a more recent, larger study by the same group [9], which is in line with our findings. In this latter report they found evidence of increasing risk with increasing parity among $B R C A 2$ mutation carriers and that BRCA1 mutation carriers with four of more children were at a significantly lower risk of developing breast cancer than nulliparous carriers [9]. In contrast, we found evidence that increasing parity was protective among both $B R C A 1$ and $B R C A 2$ mutation carriers, and that $B R C A 1$ mutation carriers with two or more offspring had a significantly lower breast cancer risk.

Our results are more in line with a recently published study by Andrieu and colleagues [19]. The estimates for the effects of parity from both studies are in the same direction and in some cases of similar magnitude. Andrieu and colleagues found that BRCA1 mutation carriers who had their first full-term preg- nancy after the age of 30 years had a significantly lower risk of developing breast cancer. We did not find a significant evidence for this in the present study, but the confidence interval of our estimate includes the estimate of Andrieu and colleagues. As did Andrieu and colleagues [19], we found a significant association for breast cancer risk and pregnancy at older ages among BRCA2 mutation carriers. One hundred and forty-six carriers used in the present analysis were also used in the analysis by Andrieu and colleagues. We repeated our analysis by excluding those records. The results were virtually the same as those already presented, with similar conclusions (results not shown). The data overlap alone therefore does not explain the agreement between the two studies. Both the present analysis and that by Andrieu and colleagues [19] were performed with a weighted Cox regression approach, 
which may further contribute to the consistency between the studies.

As described above, our analyses also included obligate carriers. Since many of these obligate carriers are mothers of known carriers and are more likely to be affected, this may introduce some bias because they are by definition parous. We therefore repeated all the above analyses, excluding all obligate carriers (142 subjects). The estimated HRs were very similar to those obtained with the full data set (data not shown). Thus, there was no evidence that the inclusion of obligate carriers biased the results.

A major issue in the analysis of parity in BRCA1 and BRCA2 mutation carriers is that the decision to opt for genetic testing may itself be related to parity, because parous women may be more concerned to be tested. If the size of this selection bias differs between affected and unaffected carriers, this will bias the estimated risk associated with parity. This is an issue in all retrospective studies based on families opting for genetic testing, from which most of the relevant data can be obtained. We have attempted to reduce this possible bias by including information on reproductive history on all known carriers, including those who are obligate carriers or who have died from a relevant cancer. However, the possibility of selection bias cannot be ruled out. Population-based or prospective studies could avoid such biases, but the former are difficult to conduct and the latter will take many years to complete.

\section{Conclusion}

Our results indicate that the relative risk of breast cancer associated with parity is similar to that in the general population. However, further larger studies are required to clarify the effect of age at first live birth on breast cancer risk among mutation carriers. Because BRCA1 and BRCA2 mutation carriers are susceptible to a much higher risk of breast cancer than noncarriers, the corresponding absolute differences in risk between parous and nulliparous carriers may be substantial. For illustration purposes consider an unaffected BRCA1 mutation carrier who is 40 years old. On the basis of the $B R C A 1$ breast cancer incidence rates estimated by Antoniou and colleagues [1], the risk of developing breast cancer by the age of 70 years is $60 \%$. Assuming that the estimated HR of 0.54 associated with parity applies to BRCA1 mutation carriers and using the same method as described by Mitchell and colleagues [24], the breast risk by 70 years of age for this mutation carrier is estimated to be $40 \%$ if she is parous and $61 \%$ if she is nulliparous. Thus, risk estimates used in genetic counselling could be improved by incorporating reproductive history, in a similar manner to that recently demonstrated for mammographic density [24]. However, given the inconsistencies between studies and the uncertainties in the age-specific risks, further large and preferably prospective studies will be required to provide more reliable absolute risk estimates.

\section{Competing interests}

The authors declare that they have no competing interests.

\section{Authors' contributions}

DGE was responsible for the conception and design of the study. DGE, FL, ERM and E Woodward provided the study patients. DGE, AS and E Watson collected and assembled the data. ACA, DFE and DGE performed the data analysis and interpretation. ACA, DFE and DGE wrote the manuscript. ACA, AS, ERM, E Woodward, FL, DFE and DGE read and approved the final manuscript.

\section{Acknowledgements}

The Breast Cancer Research Trust (BCRT) and the Genesis Appeal provided financial support. DFE is a Principal Research Fellow of Cancer Research UK. Statistical analysis was supported by Cancer Research UK.

\section{References}

1. Antoniou A, Pharoah PD, Narod S, Risch HA, Eyfjord JE, Hopper JL, Loman N, Olsson H, Johannsson O, Borg A, et al:: Average risks of breast and ovarian cancer associated with BRCA1 or BRCA2 mutations detected in case series unselected for family history: a combined analysis of 22 studies. Am J Hum Genet 2003, 72:1117-1130.

2. Antoniou AC, Pharoah PD, McMullan G, Day NE, Stratton MR, Peto J, Ponder BJ, Easton DF: A comprehensive model for familial breast cancer incorporating BRCA1, BRCA2 and other genes. Br J Cancer 2002, 86:76-83.

3. King MC, Marks JH, Mandell JB: Breast and ovarian cancer risks due to inherited mutations in BRCA1 and BRCA2. Science 2003, 302:643-646.

4. Narod SA: Modifiers of risk of hereditary breast and ovarian cancer. Nat Rev Cancer 2002, 2:113-123.

5. Collaborative Group on Hormonal Factors in Breast Cancer: Breast cancer and breastfeeding: collaborative reanalysis of individual data from 47 epidemiological studies in 30 countries, including 50302 women with breast cancer and 96973 women without the disease. Lancet 2002, 360:187-195.

6. Clavel-Chapelon F, E3N-EPIC Group: Differential effects of reproductive factors on the risk of pre- and postmenopausal breast cancer. Results from alarge cohort of French women. Br J Cancer 2002, 86:723-727.

7. Negri E, La Vecchia C, Bruzzi P, Dardanoni G, Decarli A, Palli D, Parazzini F, Rosselli del Turco M: Risk factors for breast cancer: pooled results from three Italian case-control studies. $A m \mathrm{~J}$ Epidemiol 1988, 128:1207-1215.

8. Chang-Claude J, Becher H, Eby N, Bastert G, Wahrendorf J, Hamann U: Modifying effect of reproductive risk factors on the age at onset of breast cancer for German BRCA1 mutation carriers. J Cancer Res Clin Oncol 1997, 123:272-279.

9. Cullinane CA, Lubinski J, Neuhausen SL, Ghadirian P, Lynch HT, Isaacs C, Weber B, Moller P, Offit K, Kim-Sing C, et al:: Effect of pregnancy as a risk factor for breast cancer in BRCA1/BRCA2 mutation carriers. Int J Cancer 2005, 117:988-991.

10. Hartge P, Chatterjee N, Wacholder S, Brody LC, Tucker MA, Struewing JP: Breast cancer risk in Ashkenazi BRCA1/2 mutation carriers: effects of reproductive history. Epidemiology 2002, 13:255-261.

11. Rebbeck TR, Kantoff PW, Krithivas K, Neuhausen S, Blackwood MA, Godwin AK, Daly MB, Narod SA, Garber JE, Lynch HT, et al.: Modification of BRCA1-associated breast cancer risk by the polymorphic androgen-receptor CAG repeat. Am J Hum Genet 1999, 64:1371-1377.

12. Jernstrom $H$, Lerman $C$, Ghadirian $P$, Lynch $H T$, Weber B, Garber J, Daly M, Olopade OI, Foulkes WD, Warner E, et al.: Pregnancy and risk of early breast cancer in carriers of BRCA1 and BRCA2. Lancet 1999, 354:1846-1850.

13. Tryggvadottir L, Olafsdottir EJ, Gudlaugsdottir S, Thorlacius S, Jonasson JG, Tulinius H, Eyfjord JE: BRCA2 mutation carriers, 
reproductive factors and breast cancer risk. Breast Cancer Res 2003, 5:R121-R128.

14. Rebbeck TR, Wang Y, Kantoff PW, Krithivas K, Neuhausen SL, Godwin AK, Daly MB, Narod SA, Brunet JS, Vesprini D, et al.: Modification of BRCA1 - and BRCA2-associated breast cancer risk by AIB1 genotype and reproductive history. Cancer Res 2001, 61:5420-5424.

15. Breast Cancer Information Core [http://research.nhgri.nih.gov/ bic/]

16. Antoniou AC, Goldgar DE, Andrieu N, Chang-Claude J, Brohet $R$, Rookus MA, Easton DF: A weighted cohort approach for analysing factors modifying disease risks in carriers of high-risk susceptibility genes. Genet Epidemio/ 2005, 29:1-11.

17. Huber PJ: The behavior of maximum likelihood estimates under non-standard conditions. In Proceedings of the Fifth Berkeley Symposium in Mathematical Statistics and Probability Volume 1. Edited by: Le Cam LM, Neyman F. Berkeley, University of California Press; 1967:221-233.

18. Lin DY, Wei LJ: The robust inference for the Cox proportional hazards model. J Am Statist Assoc 1989, 84:1074-1078.

19. Andrieu N, Goldgar D, Easton DF, Rookus $M$, Brohet R, Antoniou AC, Peock S, Evans G, Eccles D, Douglas F, et al.: Pregnancies, breast-feeding and breast cancer risk in the International BRCA1/2 carrier Cohort Study (IBCCS). J Natl Cancer Inst 2006, 98:535-544.

20. Kelsey JL, Gammon MD, John EM: Reproductive factors and breast cancer. Epidemiol Rev 1993, 15:36-47.

21. Beral V, Reeves G: Childbearing, oral contraceptive use, and breast cancer. Lancet 1993, 341:1102.

22. Lambe M, Hsieh C, Trichopoulos D, Ekbom A, Pavia M, Adami HO: Transient increase in the risk of breast cancer after giving birth. N Engl J Med 1994, 331:5-9.

23. Lakhani SR, Reis-Filho JS, Fulford L, Penault-Llorca F, van der Vijver M, Parry S, Bishop T, Benitez J, Rivas C, Bignon YJ, et al.: Prediction of BRCA1 status in patients with breast cancer using estrogen receptor and basal phenotype. Clin Cancer Res 2005, 11:5175-5180.

24. Mitchell G, Antoniou AC, Warren R, Peock S, Brown J, Davies R, Mattison J, Cook M, Warsi I, Evans DG, et al:: Mammographic density and breast cancer risk in BRCA1 and BRCA2 mutation carriers. Cancer Res 2006, 66:1866-1872. 